\title{
Hypercellular Bone Marrow
}

National Cancer Institute

\section{Source}

National Cancer Institute. Hypercellular Bone Marrow. NCI Thesaurus. Code C35788.

An abnormal finding in a bone marrow aspirate or biopsy specimen indicating increased

cellularity. It can result from hyperplasia of one or more hematopoietic cell lines or

malignant neoplasms that affect the bone marrow. 